\title{
The Relationship between Optimism-Pessimism and Personality Traits among Students in the Hashemite University
}

\author{
Ahmad M. Mahasneh ${ }^{1}$, Zohair H. Al-Zoubi ${ }^{2} \&$ Omar T. Batayeneh ${ }^{3}$ \\ ${ }^{1}$ Department of Educational Psychology, Faculty of Educational Science, Hashemite University, Jordan \\ ${ }^{2}$ Department of Curricula, Faculty of Educational Science, Hashemite University, Jordan \\ ${ }^{3}$ Faculty of Arts, Hashemite University, Jordan \\ Correspondence: Ahmad M. Mahasneh, Department of Educational Psychology, Faculty of Educational Science, \\ Hashemite University, Jordan. E-mail: dahmadmahasneh1975@yahoo.com
}

\author{
Received: May 16, 2013 Accepted: July 1, $2013 \quad$ Online Published: July 22, 2013 \\ doi:10.5539/ies.v6n8p71 URL: http://dx.doi.org/10.5539/ies.v6n8p71
}

\begin{abstract}
This study aimed to examine the correlation between optimism - pessimism and personality traits (extraversion, introversion, emotional stability and neuroticism), also aimed to identify the prevalence of optimism and pessimism in the study sample according to the variable sex, academic specialization, level of study, and grade point average. The study sample consisted of (534) students among undergraduate students enrolled in the Hashemite University during the summer semester 2010/2011.

Results of study revealed that: A positive correlation relationship and statistically significant between optimism and introversion. Statistically significant positive correlation relationship between pessimism emotional equilibrium, and the pessimism emotion. Statistically significant negative correlation relationship between pessimism and extraversion, and between pessimism and introversion. Differ in the prevalence of optimism in three levels (high, moderate, and low) according to the variables sex, area of study, level of study, and grade point average. Different ratios of the three levels is widespread pessimism (high, moderate, and low) according to the variables sex, area of study, level of study, and grade point average. Statistically significant differences between males and females in the prevalence of trait optimism in favor of male students. The differences are statistically significant at the level of significance $(0.05)$ between the academic level (first, second, third, and fourth) in the trait of optimism for the benefit of students who are in the level of the first, second, and third year. The presence of significance interaction between sex and grade point average on a feature of pessimism. The presence of significance interaction between specialization and grade point average on a feature of pessimism.
\end{abstract}

Keywords: optimism, pessimism, personality, Hashemite University

\section{Introduction}

In spite of the importance of the concept of optimism and pessimism in the mankind life in general, and the psychological studies in particular, the interest history in these concepts does not go any further beyond the two past decades, when they attracted the attention of many researchers in the personality, socio-psychology, clinical psychology and health sciences domains (Shukri, 1999).

The theorist of learned deficit theory sees that the mechanism responsible of acquiring optimism-pessimism is embedded in the thinking style practiced by the individual in facing the annoying and pleasing situations. This is also termed as the "optimistic interpretative method and pessimistic interpretative method" (Seligman, 1991). Seligman further defined optimism as "how people interpret themselves in cases of successes and failures (Seligman, 1990). Optimistic people see that failure is due to some changeable thing, so as to be able to succeed in the next time. On the other hand, pessimistic people burden themselves with blame. In this interpretive pattern, the negative interpretations of persons concerning the past events influence their expectation to have control over the future events, and subsequently, they influence the feelings and behavior (Maruta, 2000). If someone experiences an annoying situation, he/she tends most often to adopt a certain image of the cause for the occurrence of such annoying situation. The closer are the perceived reasons of the situation to the person's ability to control and govern, the more the likely he/she will face the situation effectively; that is exactly the optimism (Seligman, 1991). 
Seligman sees that everybody passes through defeat, rejection and failure to a certain extent through his/her life. In spite of the failure and rejection people encounter in their lives, some seek to overcome this failure, while others succumb to failure. So, Seligman sees that the way people substantially interpret their failures and defeats makes the difference among them in optimism and pessimism (Walker \& Brokow, 2000). Seligman notes in his research works on optimism and pessimism that optimistic people are superior to the pessimistic in their ability to face depression. Accordingly, they are goal achievers in their works, and mostly physically healthy (Seligman, 2003).

Scheier \& Carver (1985) "Cited in Abdel Khaleq and Al-Ansari, 1995", defined optimism as "the positive view, loving life and belief in the possibility of good occurrences, or the good aspect of things, rather than the bad aspect." They added in a more recent text (1987) that optimism is a readiness lies inside the single individual, concentrated in the general expectation that good or positive things will happen, i.e. expectation of positive results of the forthcoming events.

Abdel Khaleq (2000) defines optimism by that it is a rejoicing view of the future, making the person expects better, anticipates occurrence of goodness, and looks forward for success. On the other hand, pessimism is a negative anticipation of the events to come, making the person expects worst things to happen, and anticipates badness, failure and disappointment.

No doubt that disagreement is wide among researchers in looking at the relation between the optimism and pessimism concepts. Thus, we shall refer to two trends, at least, in this relation:

First, optimism and pessimism are two separate traits, yet interrelated, meaning that each trait has a relatively independent continuum, combines the different degrees on the one trait; and every person has a site on the optimism continuum that is independent from its center on the pessimism continuum. Here every traitindependently- is considered unipolar, starting from the lowest degree (may be zero) to the highest degree. The same matter is repeated -independently- with pessimism.

Second, optimism and pessimism are one single trait, but it is bipolar. In other words, the trait continuum here has two opposite poles, with every body having a one center on it, so that he/she may fall among the extreme optimism and intensive pessimism. This implies that the human, in general, cannot be extremely optimistic or very pessimistic, as he/she has a one degree on the continuum, the same is in extroversion-introversion traits (Al-Ansari, 2003).

Kelly (1955) and Nunnaly (1978) noted that the trait could be represented by a continuous line of behavior, and we attempt to locate the person's position on the line concerning a certain trait, through measurement processes. The term "continuum" means a straight line consisting of indefinite number of possible points that locate different sites of the measured trait (Allam, 2002). Based on this trend, measuring these two traits may be made by measuring optimism alone or pessimism alone, as the traits are opposite, and the degree of one is the reverse value of the other, i.e. high optimistic degree means low pessimistic degree, and vice versa.

The significance of the study of optimism-pessimism lies in the importance of its relationship to the different aspects of the normal and abnormal human personality. Seligman's Theory in Attribution assured that the method through which we interpret things or evens is more influential on our current and future behavior than their occurrences; having either good or bad implications upon our mental and physical health (Al-Hajjar, 1989).

Results of many previous studies, such as Al-Ansari (2003) Cohen (2001), Lennings (2000), Hollnagel, et al (2000), and Achat, et al (2000) indicate that optimism is positively related to a number of the normal variables such as: mental health, physical health, life satisfaction, happiness, effective encounter of pressures, successful problem solving, occupational performance, good academic performance, extroversion, work motivation, production quality, self-control, low levels of pain and tiredness.

About the differences between the two genders in the means of optimism-pessimism, some studies such as Abdel Khaleq's (1995) on the students of the University of Kuwait, revealed high levels of optimism degrees mean with the males as compared with females, and the reverse was true in pessimism.

Mcsteen (1997) concluded that the mental rigidity or toughness was a good predictor on the variance of the optimistic disposition; the control direction and family awareness contributed to the high level of optimistic disposition and mental rigidity. The study further indicated that the contribution of mental rigidity, control direction and family awareness accounted for $53 \%$ of the total variance of the optimistic disposition.

Barakat (1998) concluded that students were optimistic, and found the existence of statistically significant differences in optimism and pessimism according to the academic specialization variable, with differences were 
in favor of the scientific specialization students. Meanwhile, there were no statistically significant differences by gender, social status, or age variables.

Abdel Latif and Hamadeh (1998) concluded that there are significant differences between the two genders in optimism, whereas they were not apparent in pessimism. A positive correlation appeared between optimism and extroversion, and between optimism and psychosis.

Al-Masha'an (2000) found statistically significant differences between males and females in optimism and mental and psychical disorders; but males were more optimistic than females. There were not statistically significant differences between males and females in pessimism. The result showed a negative significant correlation between optimism, pessimism, psychological disorders and life pressures.

Maruta, et al (2000) found a inverse relationship between optimism and both mental and psychical disorders. In other words, optimism leads person to a better life and a desired interpretation of its events; and supports the good physical health. At the same time, the good physical health leads a better expectation in life, meaning that there is an interaction between health and optimism. At the event of any illness, optimistic people follow a more careful medical regime duly prescribed for them, and turn away the behaviors that caused such illness. The reverse is true in pessimism; the recurrent illness may lead the person to expect the worst, i.e. pessimism. Furthermore, pessimism weakens the immune system of the body, decreases the recovery rate and increases early death rates.

Abdel Khaleq (2000) concluded that there is a relationship between optimism-pessimism and academic achievement.

Yates (2000) aimed in his study which he conducted on the preparatory and secondary stages students and to know the relationship between optimism-pessimism and each of academic achievement and grade level; and to know the difference between the two genders in optimism-pessimism. The study concluded that there are statistically significant differences between optimism and pessimism attributed to the gender. In this concern, males were more pessimistic than females throughout the study years. The study further found statistically significant differences in optimism and pessimism attributed to the grade level, and a negative relationship between optimism and academic achievement.

Al-Anazai (2001) concluded that there were no differences between the two genders in optimism, and a positive correlation between life satisfaction, self confidence and optimism.

Ismail (2001) conducted a study aimed at prediction in optimism and pessimism through certain variables, represented in feeling psychological loneliness, control direction, death worry, economical and social condition. The most predictable variables of optimism were: feeling loneliness, control direction, death worry, and economical and social condition, respectively. On the other hand, the most predictable variables of pessimism were: control direction, feeling loneliness, death worry, and economical and social condition, respectively.

Redwan (2001) did not find differences between the two genders in pessimism. The research results indicated the linkage of the optimism- pessimism with the social relations and the individual's psychological adjustment network. A study conducted by Brissette, Scheier \& Carver (2002) on the role of optimism in creating the social networks among the university students, concluded that enjoying optimism contributes to the increase of creating social networks with the individuals and their achieving higher levels of psychological adjustment than the pessimistic individuals.

Creed, et al (2002) concluded that worried, pessimistic people have negative feelings and less positive as compared to the less worried, optimistic people; and that optimism is correlated to the high levels of life planning, discovery, and confidence in decision taking. Meanwhile, pessimism is correlated to hesitation, wonder in life and low self-esteem.

Al-Ansari (2003) concluded the existence of positive, significant relationship between optimism and extroversion and lying. Meanwhile optimism negatively correlated with each of pessimism, worry, obsessive-compulsive disorder, guilt, shame, despair, depression and nervousness. Pessimism had a negative, significant relationship with each of optimism, extroversion and lying, and positive, significant relationships with each of worry, despair, guilt and depression. The results indicated the existence of significant differences between the two genders in optimism in favor of the males, as they are more optimistic than females. Furthermore, the results showed significant differences between the two genders in pessimism in favor of the females, as they are more optimistic than males.

Yates (2002) found a positive correlation between optimism and achievement in mathematics; and she found negative correlation between pessimism and achievement in mathematics. 
Al-Himyari (2003) showed that there were no differences between the two genders in the optimism/pessimism trait.

El-Anzi (2005) concluded a statistically significant, positive relationship between optimism and academic achievement, meantime he found a statistically significant, negative relationship between pessimism and academic achievement.

O'Cconnor \& Casidy (2006) conducted a study on a university students sample aimed to identify the predictability of feeling despair through interaction between optimism and pessimism and a definite number of the future expectations of the individual. The study concluded that despair prediction is possible through the knowledge of individuals' levels of optimism and pessimism.

Al-Minshawi (2006) found a statistically significant, positive relationship between optimism, mental rigidity, emotional intelligence and academic achievement. He further found a statistically significant, negative relationship between pessimism and each of mental rigidity, emotional intelligence and academic achievement. The researcher did not find differences between the two genders in optimism.-pessimism; he found higher optimism prevalence with the first group sample than its prevalence with the fourth group sample; and the existence of statistically significant differences in optimism-pessimism attributed to the academic grade level.

\section{Statement of the Problem}

Many studies were conducted on optimism-pessimism, which focused on the relationship between them and a number of the various personality aspects with the individuals, whether positive or negative relationship. The results of many studies, such as Abdel Khaleq (2000), Cohen (2000), Al-Ansari (2003) and Redwan (2000), indicated that optimism is positively correlated with a number of normal (or positive) variables such as mental health, physical health, happiness, life satisfaction, effective encounter of the pressures, problem solving, high academic performance, extroversion, work motivation, quality of the production and self-control. On the contrary, pessimism is correlated to the abnormal pathologic variables, such as despair, failure in problem solving, worry and depression.

\section{Objectives and Research Questions}

The purpose of this study was to examine the relationship between optimism- pessimism and personality traits among the students of the Hashemite University in Jordan.

The specific study questions that guided this study were:

RQ1: What is the prevalence degree of optimism-pessimism trait at their extreme and moderate levels among the Hashemite University Students as per gender, academic specialization, academic level and accumulative average variables?

RQ2: Is there a correlation between optimism-pessimism (extroversion, introversion, emotional stability and neuroticism ) among the Hashemite University Students?

RQ3: Are there statistically significant differences in the optimism-pessimism trait among the Hashemite University students attributed to: gender, accumulative average, academic specialization, academic level)?

\section{Significance of the Study}

Based on the above about the prevalence of optimism-pessimism and their impact on the health status of the individual; and due to the particular characteristics of the Jordanian society of habits and traditions, as well as the age influences imposing new life styles on the youth, and their future ambitions, the theoretical and applied significance of this study arises from the information for researchers in psychology about the distribution of the Hashemite University on the optimism-pessimism continuum, being a bipolar, one single trait.

This study belongs to the positive psychology domain, which needs more and more studies and research works to complete this important psychology discipline; as the study is hoped to enrich the psychological field. The current study attempts to identify the prevalence rates of optimism-pessimism among a sample of the Hashemite University students. It is presumed that the university study carries positive rather than negative expectations and orientations toward the future. The study results may contribute to the orientation and guidance of the university students in general; those who are the society hope and future in improving their vision and view of the future.

In addition, this study may further be, in additional to other research and studies, beneficial to the concerned institutions in understanding the common psychological, physical and educational problems among the Hashemite university students, in order to find preventive, guidance and remedial programs that may contribute, 
in addition to the other programs of the concern, to help the youth overcome these problems, and effectively contribute in the community building and development.

\section{Methodology}

\subsection{Participants}

The study population consisted (11092) of the Hashemite University students enrolled in the summer semester for BA degree in the academic year 2010/2011, distributed over the different University Faculties. The study sample consisted of (534) male and female students (5\% of the study population) representative of the various faculties and academic levels. Four sections were selected out of the University Elective Courses the University provides for all the BA grade students.

\subsection{Instruments}

Participants completed measures of optimism- pessimism and personality traits. Each is described are following.

\subsubsection{Optimism-Pessimism Scale}

Following the revision of previous studies and literature, Al-Himyari's (2003) Scale and Al-Hakkak's (2001) Scale on optimism-pessimism, the study instrument had been constructed. It consisted of (42) items paraphrased as per Likert style, with multiple choices against each item, to select one of the five choices, which weights range from 1-5 which consist of the response always, frequently, sometimes, infrequently and never.

To verify the scale validity, it had been presented to a body of arbitrators in the counseling and psychology department of the Hashemite University to judge the scale items in terms of wording, language accuracy, clarity of the meanings and the appropriateness degree of the items to the specified domains; as well as obtain their suggestions for suitable modification, addition or deletion of the items. Relying on their suggestions, the researchers made modifications that the majority ( $80 \%$ and more) of the arbitrators proposed, purporting that the instrument possesses a high degree of content validity.

Reliability was also verified by calculating the internal consistency coefficient, employing Chronbach Alfa Equation, and a (0.78) reliability coefficient was obtained, a reliability amount that is deemed significant and sufficient for the purposes of this study.

\subsubsection{Eysenck Personality Scale}

Eysenck personality scale (Eysenck and Eysenck, 1974) was employed. This scale is widely used by many of researches in the Jordanian setting such as: Shihab (1993), Al-Halasa (1996). The scale consists of (57) items that measure two of personality dimensions. First dimension was (extroversion-introversion) with (24) items to measure, given the following numbers: $1,3,5,8,10,15,17,20,22,25,27,29,32,34,37,39,41,44,46,49,51$, 53 and 56.

The second dimension (emotional stability- neuroticism) with (24) items to measure, given the following numbers: $2,4,7,9,11,14,16,19,21,23,26,28,31,33,35,38,40,43,45,47,50,52,55$ and 57). The remaining items $(\mathrm{n}=9)$ were to measure lying were given the following numbers: $6,12,18,24,30,36,42,48$, and 54), with the responses to these items are "Yes" or No".

The appropriate response takes one grade and the inappropriate takes zero grade, the range of the individuals' grades on each of the personality dimensions between (0-24), with 13 and more indicating the first dimension of extroversion, and 12 and less indicating the same dimension of introversion.

As for the second dimension (emotional stability- neuroticism), score 12 and more indicated the person's tendency toward emotional stability, while 13 and less indicated tendency toward neuroticism.

Items measuring lying using Eysenck scale, were given 5 grades as a maximum grade to accept the interviewees' responses, and those obtaining more than 5 grades were excluded.

Scale developer indicated that he carried out the validity of the collateral construction by comparing the results of his list with the those of Modsley's, and found them enjoying high validity significance, without mentioning any quantitative value. Al-Qudah, (2006) also presented the scale items to a number of professionals at Mutah University, and he relied on the consensus ( $80 \%$ ) of 7 arbitrators, and all the items were approved because they all overran the $80 \%$ test limit.

Reliability also was approved by a number of researchers, and the scale developer calculated the reliability coefficient through retesting, and found it ranging between (0.84-0.94) (Eysenck \& Eysenck, 1974). Furthermore, Al-Husseini (1993), calculated the Arabized version of the reliability coefficient, which amounted (0.80). Al-Halasah (1996) concluded the list reliability significances through retesting which ranged between 
(0.74-0.81). For the purposes of the current study, the researcher was satisfied with the reliability significances which the above mentioned two researches obtained, based on the fact that both coefficients were almost equal.

\subsection{Data Collection}

After acquiring the instructor permission, the questionnaire administrated was during regular class periods to student in the second semester of the 2010-2011 academic year. The students received written instruction that specified the purpose of the study and explained the procedure followed while responding to the questions. In particular, the students were told that there were no rights or wrong response. Students asked to return the questionnaires to the class instructor who passed them it on to the researcher.

\subsection{Data Analysis}

The data collected from all participants were coded, entered onto the SPSS spreadsheets, and analyses using software package SPSS version 17. Descriptive statistics for all variables in this study were examined using SPSS frequencies. The minimum and maximum values of each item were examined for accuracy of data entry by inspecting any out-of-range values. No out-of-range values were found. Missing subjects were not detected either. The results of the study are addressed by each objective.

\section{Results and Discussion}

\subsection{Results Pertaining to Objective 1}

RQ1: What is the prevalence degree of optimism-pessimism trait at their extreme and moderate levels among the Hashemite University Students as per gender, academic specialization, academic level and accumulative average variables?

To answer this question, the researchers calculated the percentage of each of optimism and pessimism traits by the study variables. Table (1) shows the optimism percentage distribution among the study sample.

Table 1. Optimism distribution percentages over the study sample

\begin{tabular}{|c|c|c|c|c|c|c|c|}
\hline \multirow{3}{*}{ Sample } & \multirow{3}{*}{ No } & \multicolumn{6}{|c|}{ Optimism Levels } \\
\hline & & \multicolumn{2}{|c|}{ High 74-100 } & \multicolumn{2}{|c|}{ Moderate 48-73 } & \multicolumn{2}{|c|}{ Low $20-47$} \\
\hline & & No. & $\%$ & No. & $\%$ & No. & $\%$ \\
\hline Male Students & 292 & 4 & $1 \%$ & 136 & $47 \%$ & 152 & $52 \%$ \\
\hline Female Students & 242 & 8 & $3 \%$ & 74 & $31 \%$ & 160 & $66 \%$ \\
\hline Scientific & 261 & 25 & $10 \%$ & 110 & $42 \%$ & 126 & $48 \%$ \\
\hline Humanities & 273 & 27 & $10 \%$ & 86 & $32 \%$ & 160 & $58 \%$ \\
\hline First Year & 220 & 14 & $6 \%$ & 86 & $39 \%$ & 120 & $55 \%$ \\
\hline Second Year & 172 & 12 & $7 \%$ & 60 & $35 \%$ & 100 & $58 \%$ \\
\hline Third Year & 100 & 12 & $12 \%$ & 38 & $38 \%$ & 50 & $50 \%$ \\
\hline Fourth Year & 42 & 13 & $31 \%$ & 13 & $31 \%$ & 16 & $38 \%$ \\
\hline Excellent & 60 & 2 & $20 \%$ & 18 & $30 \%$ & 30 & $50 \%$ \\
\hline Very Good & 130 & 12 & $9 \%$ & 52 & $40 \%$ & 66 & $51 \%$ \\
\hline Good & 200 & 14 & $7 \%$ & 78 & $39 \%$ & 108 & $54 \%$ \\
\hline Acceptable & 144 & 14 & $10 \%$ & 48 & $33 \%$ & 82 & $57 \%$ \\
\hline
\end{tabular}

Table 1 indicates the following:

- There is a difference in the moderate optimism prevalence rates by gender ( $47 \%$ for males) and ( $31 \%$ for females). This may be explained by that students are more careful for learning process and academic success, which in turn will influence their future expectations and visions in a positive manner. Meanwhile, female students hold much of sufferings, pressures and fear of the future, all of which will have impact on their future expectations, and make them less optimistically feeling than male students. This study is consistent with that of Al-Ansari (1995), Abdel Latif and Hamadeh (1998), Al-Masha'an (2000) and Al-Ansari (2003), which revealed a higher optimism level with the males than that of the females, while the reverse is true on pessimism. The current study is not consistent with that of Barakat (1998), which concluded that there are no statistically significant differences in optimism and pessimism by gender variable. 
- There is a difference in the low optimism prevalence rates among the two genders, optimism rates were $52 \%$ and $66 \%$ for males and females, respectively.

- There is a difference in the moderate optimism prevalence rates among the scientific and humanities specializations students; moderate optimism prevalence among scientific specializations students was (42\%) as compared to (32\%) of the humanities specializations students. This could be explained by that the nature of the academic specialization of the study and his/her academic success, as well as absence of the problems and obstacles in the way of the academic specialization of the student, could contribute to student's feeling optimistic. The scientific specializations, by their nature, need more effort and perseverance that literary and humanities specializations, which in turn will have an effect on the optimism degree. This result is in consistency with that of Barakat (1998), which indicated the existence of statistically significant differences in optimism and pessimism by the student's academic specialization in favor of the scientific specializations students.

- There is a difference in the low optimism prevalence rates among the scientific and humanities specialization students: $48 \%$ and $58 \%$ with the scientific and humanities specializations students, respectively.

- There are differences in the optimism prevalence rates among the first, second, third and fourth years. The high optimism rates were as follows: first year $(6 \%)$, second year $(7 \%)$, third year $(12 \%)$, and fourth year (31\%). This result could be interpreted as logical and agreeing with realty, as the fourth year students are at the graduation points and getting out to the labor market, a matter seen by many students as very difficult to access; and students wish to form new families. All such concerns impose different types of pressures that would reflect on the individual's future expectations.

- There are differences in the high optimism prevalence rates among the students ranking excellent, very good, good and acceptable. The prevalence rates were: $(20 \%),(9 \%),(7 \%)$ and $(10 \%)$ for the students obtaining: excellent, very good, good and acceptable ranks, respectively. These rates could be interpreted by that the higher achiever the student is the more he/she feels optimistic, as the academic comfort is reflected on the student's psych and his/her reading of the future, as well as the rational thinking style based on logics.

The percentage rates of the pessimism trait were calculated by the study variables. Table 2 indicates these rates.

Table 2. Pessimism distribution rates among the study sample

\begin{tabular}{llllllll}
\hline \multirow{2}{*}{ Sample } & \multicolumn{3}{c}{ Pessimism Levels } & \multicolumn{2}{l}{ Moderate $48-73$} & \multicolumn{2}{l}{ Low 20-47 } \\
& No & \multicolumn{2}{l}{ High 74-100 } & No. & $\%$ & No. & $\%$ \\
\hline Male Students & 292 & 4 & $1 \%$ & 78 & $27 \%$ & 208 & $72 \%$ \\
Female Students & 242 & 8 & $3 \%$ & 47 & $19 \%$ & 187 & $78 \%$ \\
Scientific & 261 & 31 & $12 \%$ & 70 & $27 \%$ & 160 & $61 \%$ \\
Humanities & 273 & 27 & $10 \%$ & 65 & $24 \%$ & 181 & $70 \%$ \\
First Year & 220 & 16 & $7 \%$ & 51 & $23 \%$ & 153 & $70 \%$ \\
Second Year & 172 & 14 & $8 \%$ & 44 & $26 \%$ & 114 & $66 \%$ \\
Third Year & 100 & 14 & $14 \%$ & 26 & $26 \%$ & 60 & $60 \%$ \\
Fourth Year & 42 & 4 & $10 \%$ & 19 & $45 \%$ & 19 & $45 \%$ \\
Excellent & 60 & 12 & $20 \%$ & 18 & $30 \%$ & 30 & $50 \%$ \\
Very Good & 130 & 16 & $12 \%$ & 29 & $22 \%$ & 85 & $66 \%$ \\
Good & 200 & 16 & $8 \%$ & 48 & $24 \%$ & 136 & $68 \%$ \\
Acceptable & 144 & 4 & $3 \%$ & 56 & $31 \%$ & 95 & $66 \%$ \\
\hline
\end{tabular}

Table 2 indicates the following:

- There are differences in the pessimism prevalence rates between the two genders, $27 \%$ for males and $19 \%$ for females.

- There are no differences in the pessimism prevalence rates with its three levels (high, moderate and low) among the scientific faculties' students and humanities faculties' students. High pessimism rates among the 
scientific and humanities faculties students were $(12 \%)$ and $(10 \%)$, respectively. Moderate pessimism rates were (27\%) and (24\%) among the scientific and humanities faculties students, respectively. Finally, low pessimism rates were (61\%) and (66\%) among the scientific and humanities faculties students, respectively. Researchers ascribe this to that the Hashemite University students are living the same conditions, whether in the scientific or humanities faculties, they are all governed by the same regulations and instructions inside the University. They are further experiencing the same obstacles and difficulties that increase or decrease pessimism rates.

- There are differences in the low pessimism prevalence rates among the first, second, third and fourth year students. The low pessimism rates among the students of these years were: $(70 \%),(66 \%),(60 \%)$ and $(45 \%)$ among the first, second, third and fourth year students, respectively. On the other hand the moderate pessimism rates among the same students were: $(23 \%),(26 \%),(26 \%)$ and $(45 \%)$ among the first, second, third and fourth year students, respectively. This could be explained by that the newcomers are more pessimistic, because the university life is quite different from that of the school where they were recently graduated. This rate becomes less as they are more advanced in the duration and academic levels in the university, grading throughout the study years. Quite noticeable that this rate decreases in the fourth year because the student of this year interacts more with the graduation year and preparation for the work life, thinking of the future, marriage and the like of thoughts related with the community factuality outside the university walls.

- There are differences in the low pessimism prevalence rates among the students who achieved excellent, very good, good and acceptable rankings. In this concern, low pessimism rates among the excellent, very good, good and acceptable rank achievers were (50\%), (66\%), (68\%) and (66\%), respectively. Students of high accumulative averages are less pessimistic than those achieving low accumulative averages. This could be imputed to that the high achiever students possess a more optimistic view of life and realty; they have more adaptability to the different conditions and life situations; and they enjoy more positive self-concept than the lower achiever students who look at life through a black lenses.

\subsection{Results Pertaining to Objective 2}

RQ2: Is there a correlation between optimism-pessimism (extroversion, introversion, emotional equilibrium- affection) among the Hashemite University Students?

To answer this question, the correlation coefficient among the grades of the study sample on the optimism-pessimism scale and the total grades on Eyeznck Personality Scale on the extroversion and affection dimension was calculated. Table 3 shows the correlation coefficient among the variables.

Table 3. Correlation coefficient array among the study variables

\begin{tabular}{lllll}
\hline Variables & Extroversion & Introversion & $\begin{array}{l}\text { Emotional } \\
\text { stability }\end{array}$ & neuroticism \\
\hline Optimism & -.002 & $* .279$ & -.009 & .063 \\
Pessimism & $* *=.229$ & $* *-311$ & $* * .335$ & $* * .285$ \\
\hline
\end{tabular}

- Statistically significant at $(\underline{\alpha}<.05)$ level.

- Statistically significant at $(\underline{\alpha<} .01)$ level

Table 3 indicates a positive correlation between optimism and introversion, and no correlation between each of extroversion, emotional stability and neuroticism. Meanwhile, there was a negative correlation between pessimism, extroversion and introversion, and a positive correlation among pessimism, emotional stability and neuroticism. This result is in agreement with the previous studies conducted by Abdel Latif \& Hamada (1998), and Al-Ansari (2003), which results revealed a positive correlation among optimism, extroversion, pessimism and neuroticism. The results of this study further revealed a negative correlation between pessimism-extroversion and between optimism- neuroticism.

\subsection{Results Pertaining to Objective 3}

RQ3: Are there statistically significant differences in the optimism-pessimism trait among the Hashemite University students attributed to: gender, accumulative average, academic specialization and academic level)? 
To answer this question, the means and standard deviations (M's and SD's) were calculated for the grades of the study sample students on the optimism-pessimism scale by gender, academic specialization, academic level and accumulative average variables, as duly shown in Table 4.

Table 4. M's and SD's of the study sample students by variables

\begin{tabular}{lllll}
\hline Variables & Optimism & & Pessimism & \\
& M & SD & M & SD \\
\hline Male Students & 42.20 & 8.67 & 40.93 & 12 \\
Female Students & 44.84 & 7.20 & 40.60 & 13.83 \\
Scientific Faculties & 46.47 & 7.52 & 41.42 & 14.20 \\
Humanities Faculties & 45.03 & 8.11 & 40.07 & 12.09 \\
First Year & 45.80 & 8.70 & 40.33 & 13.48 \\
Second Year & 45.83 & 7.51 & 41.39 & 12.10 \\
Third Year & 45.65 & 6.04 & 40.21 & 14.75 \\
Fourth Year & 40 & 12.03 & 44 & 5.77 \\
Excellent & 46.50 & 8.89 & 36.16 & 11.86 \\
Very Good & 46.02 & 6.87 & 40.02 & 15.02 \\
Good & 45.59 & 8.08 & 41.69 & 13.13 \\
Acceptable & 45.50 & 8.17 & 40.88 & 11.53 \\
\hline
\end{tabular}

To identify the means on the optimism trait, ANOVA was made as shown in Table 5.

Table 5. Results of the ANOVA to identify the main and interaction impacts among gender, academic specialization, academic level and accumulative average

\begin{tabular}{llllll}
\hline Variance Source & $\begin{array}{l}\text { Total } \\
\text { Squares }\end{array}$ & $\begin{array}{l}\text { Liberty } \\
\text { Degree }\end{array}$ & $\begin{array}{l}\text { Square } \\
\text { Average }\end{array}$ & F Value & $\beta$ \\
\hline Gender & 340.876 & 1 & 340.876 & 6.560 & $.010^{*}$ \\
Specialization & 112.322 & 1 & 112.322 & 2.194 & .139 \\
Academic Level & 809.896 & 3 & 269.865 & 5.271 & $.001^{*}$ \\
Accumulative Average & 393.818 & 3 & 131.273 & 2.564 & .055 \\
Gender x Specialization & 470.342 & 1 & 470.342 & 9.187 & .003 \\
Gender x Level & 89.963 & 2 & 44.982 & .879 & .416 \\
Gender x Average & 143.969 & 3 & 47.990 & .937 & .423 \\
Specialization x Level & 7.467 & 2 & 3.734 & .073 & .930 \\
Specialization x Average & 706.661 & 3 & 235.554 & 4.601 & .004 \\
Level x Average & 1341.375 & 6 & 223.562 & 4.367 & $.000^{*}$ \\
Gender x Specialization x Level & 27.471 & 2 & 13.735 & .268 & .765 \\
Gender x Level x Average & 223.058 & 4 & 55.764 & 1.089 & .362 \\
Gender x Specialization x Average & 114.649 & 2 & 57.325 & 1.120 & .328 \\
Level x Specialization x Average & 1529.483 & 5 & 305.897 & 5.975 & $.000^{*}$ \\
Gender x Specialization x Level & 130.415 & 1 & 130.415 & 2.547 & .111 \\
Average & & & & & \\
Error & 17765.100 & 496 & 51.196 & & \\
Total & 835378.000 & 534 & & & \\
\hline
\end{tabular}

Table 5 shows the following:

- There are statistically significant differences at (0.05) significance level between males and females on the optimism trait in favor of males.

- There are statistically significant differences at (0.05) significance level between the academic level (first, second, third and fourth year) on the optimism trait in favor of students of first, second and third academic year.

- There is an interaction at the (0.05) significance level between the academic specialization and accumulative average on optimism trait. 
- There is an interaction at the (0.05) significance level between the academic specialization, academic level and accumulative average on optimism trait.

- There is no interaction between: gender, academic level, academic specialization and accumulative average on optimism trait.

To identify the differences of the means among the variables on the pessimism trait, variance analysis was mad as show in Table 6.

Table 6. Results of the variance analysis to identify the main and interactive effects between each of: gender, specialization, accumulative average and academic level on pessimism

\begin{tabular}{llllll}
\hline Variance Source & $\begin{array}{l}\text { Total } \\
\text { Squares }\end{array}$ & $\begin{array}{l}\text { Liberty } \\
\text { Degree }\end{array}$ & $\begin{array}{l}\text { Square } \\
\text { Average }\end{array}$ & F Value & $\beta$ \\
\hline Gender & 153.015 & 1 & 153.015 & .940 & .333 \\
Specialization & 1234.346 & 3 & 1234.346 & 7.582 & $.006^{*}$ \\
Academic Level & 548.440 & 1 & 182.813 & 1.123 & .340 \\
Accumulative Average & 196.978 & 3 & 65.659 & .403 & .751 \\
Gender x Specialization & 226.204 & 2 & 226.204 & 1.389 & .239 \\
Gender x Level & 160.454 & 1 & 80.227 & .493 & .611 \\
Gender x Average & 2720.397 & 3 & 906.799 & 5.570 & .001 \\
Specialization x Level & 328.614 & 2 & 164.307 & 1.009 & .366 \\
Specialization x Average & 2350.031 & 6 & 783.344 & 4.811 & $.003^{*}$ \\
Level x Average & 2676.653 & 3 & 446.109 & 2.740 & $.013^{*}$ \\
Gender x Specialization x Level & 93.473 & 2 & 46.736 & .287 & .751 \\
Gender x Level x Average & 1495.526 & 4 & 373.882 & 2.296 & $.059^{*}$ \\
Gender x Specialization x Average & 294.084 & 2 & 147.042 & .903 & .406 \\
Level x Specialization x Average & 966.007 & 5 & 193.201 & 1.187 & .315 \\
Gender x Specialization x Level & 170.557 & 1 & 170.557 & 1.048 & .307 \\
Average & & & & & \\
Error & 56494.145 & 496 & 162,807 & & \\
Total & 710592.000 & 534 & & & \\
\hline
\end{tabular}

Table 6 indicates the following:

- There are statistically significant differences at (0.05) significance level between gender and accumulative average on the pessimism trait.

- There are statistically significant differences at (0.05) significance level between the specialization and accumulative average on the optimism trait.

- There is no interaction between gender, academic specialization, academic level and accumulative average on the pessimism trait.

\section{Recommendations}

- Study of the factorial ingredients of optimism and pessimism with the university students and identifying the difference degrees of these ingredients by difference of type and culture.

- Study of the relationship between optimism, pessimism and efficiency of the academic self.

- Conducting other studies addressed other personal variables

- Study of the relationship between mental health and each of optimism and pessimism.

\section{References}

Abdel Khaleq, A. M., \& Al-Ansari, B. (1995). Optimism and Pessimism- An Arabic Study in Personality", In the $2^{\text {nd }}$ International Conference of the Special Need, Gifted and Disabled Children Psychological Counseling. 25-27 December 1995. Conference Research, 1, 131-152, Ain Shams University, Cairo.

Abdel Khaleq, A. M. (2000). Optimism and Pessimism: Arabic Studies Presentation. Psychology Journal, 57(14), 6-27. 
Abdel Latif, H., \& Hamada, L. (1998). Optimism and Pessimism and their Relationship to the Personality Two Dimensions (Extroversion and Psychosis). Educational Journal, 36(1), 83-104.

Achat, H., Kawachi, I., Spiro, A., III, DeMolles, D. A., \& Sparrow, D. (2000). Optimism and depression as predictors of physical and metal health functioning: The Normative Aging Study. Annals of Behavioral Medicine, 22, 127-130. http://dx.doi.org/10.1007/BF02895776

Al-Ansari, B. (2002). Preparation of an Arabic Image of the Scale for Life Orientation as an Optimism Scale. Social Sciences Journal, 30(4), 757-812

Al-Ansari, B. (2003). Optimism and Pessimism: There Measurement and Relationships with Certain Personality Variables among Kuwait University Students. Al-Resala, 192, 23 ${ }^{\text {rd }}$ Year Book, Scientific Publication Council, University of Kuwait, Kuwait.

Al-Anzi, F. O. (2001). Feeling Happy and its Relationship to Certain Personality Traits: A Comparative Correlation Study, Comparing between Males and Females. Psychological Studies Journal, 11(3), 351-337.

Al-Hajjar, M. (1989). Contemporary Behavioral Medicine, Research in the Most Important Medical Psychology and Behavioral Therapy. Dar-el-Malayeen, Beirut.

Al-Hakkak, W. (2001). Construction of Optimism and Pessimism Measurements among Baghdad University Students. Unpublished MA Thesis, Faculty of Education, University of Baghdad, Iraq.

Al-Halasah, H. K. (1996). Relation of Certain Personality Traits to the Accomplishment Motive among the $11^{\text {th }}$ Grade Students. Unpublished MA Thesis, Mutah University, Jordan.

Al-Himyari, A. F. (2003). Measurement of Optimism-Pessimism of the University Students in Yemen. Journal of the Faculty of Education- Ain Shams University, 28(2), 143-158.

Al-Husseini, M. K. E. (1993). Personal Traits that Distinguish the Depressed and Non-Depressed. Unpublished MA Thesis, University of Jordan.

Allam, S. E. (2002). Educational and Psychological Measurement and Evaluation, its Basics, Applications and Contemporary Orientations. Dar-el-Fikr Al-Arabi, Cairo.

Al-Mash'an, O. S. (2000). Optimism and Pessimism and their Relationships to the Psychological and Physical Disorders and Life Event Pressures with the University Student. Psychological Studies, 10, 505-532.

Azar, I. (2006). Relationship between quality of life, hardiness, self- esteem amongst employed and unemployed women in Zabol. Iran Psychiatry, 1, 104-111.

Barakat, Z. (1998). Optimism and Pessimism Psychology and their Relationship to Certain Student-Related Variable. Psychometric and Educational Journal, 1, 55-76.

Brissette, I., Scheier, M., \& Carver, C. S. (2002). The role of optimism in social network development, coping, and psychological adjustment during a life transition. Journal of Personality and Social Psychology, 82, 102-111. http://dx.doi.org/10.1037/0022-3514.82.1.102

Cohen, L., de Moor, C., \& Amato, R. J. (2001). The association between treatmentspecific optimism and depressive symptomatology in patients enrolled in a phase I cancer clinical trial. Cancer, 91, 1949-1955. http://dx.doi.org/10.1002/1097-0142(20010515)91:10<1949::AID-CNCR1218>3.0.CO;2-A

Creed, P. A., Patton, W., \& Bartrum, D. (2002). Multidimensional properties of the LOT-R: Effects of optimism and pessimism on career and well-being related variables in adolescents. Journal of Career Assessment, 10(1), 37-52. http://dx.doi.org/10.1177/1069072702010001003

El-Anzi, F. O. (2005). Academic achievement and its relationship with anxiety, self-esteem, optimism and pessimism in Kuwaiti students. Social Behavior and Personality, 33, 95-104. http://dx.doi.org/10.2224/sbp.2005.33.1.95

Fabbri, S., Kapur, N., Wells, A., \& Creed, F. (2000). Emotional, cognitive, and behavioral characteristics of medical outpatients: A Preliminary Analysis. Psychosomatics, 42(1), 74-77. http://dx.doi.org/10.1176/appi.psy.42.1.74

Hollnagel, H., Malterud, K., \& Witt, K. (2000). Men's self-assessed personal health resources. Approaching patients' strong points in general practice. Family Practice, 17, 529-34. http://dx.doi.org/10.1093/fampra/17.6.529 
Isaacowitz, D. M., \& Seligman, M. E. P. (2001) Is pessimism a risk factor for depressive mood among community - dwelling older adults? Behavior Research and Therapy, 39(3), 255-272. http://dx.doi.org/10.1016/S0005-7967(99)00178-3

Ismail, A. (2001). Optimism and Pessimism and Certain Psychological Variables with a Sample of Umm -el-Qura University Students. Educational Journal, 60(15), 51-81.

Kelly, G. A. (1955). The Psychology of Personal constructs. New York: Norton.

Lennings, C. J. (2000). Optimism, satisfaction and time perspective in the Elderly. International Journal of Aging Human Development, 51(3),167-181. http://dx.doi.org/10.2190/06GK-WHER-37XC-BTRY

Maruta, T., Colligan, R. C., Malinchoc, M., \& Offord, K. P. (2000). Optimists vs. pessimists: Survival rate among medical patients over a 30-year period. Mayo Clinical Proceedings, 75, 140-143.

Mcsteen, P. (1997). An investigation of the relationship between dispositonal optimison and family environmen Psychological hardiness and Lows of control. Dissertation Abstracts International.

Nunnally, J. C. (1978). Psychmetric theory. New York: Me Grow- Hill.

O'Connor, R. C., \& Cassidy, C. (2007). Predicting hopelessness: The interaction between optimism/pessimism and specific future expectancies. Journal of Cognition and Emotion, 21, 596-613. http://dx.doi.org/10.1080/02699930600813422

Redwan, S. (2001). Depression and Pessimism: A Comparative Correlation Study. Educational and Psychological Journal, 2(1), 13-48.

Roberts, R. E., Roberts, C. R., \& Chen, I. G. (2000). Fatalism and risk of adolescent depression. Psychiatry, 63(3), 239-252.

Scheier, M. F., \& Carver, C. S. (1985). Optimism, coping and health: Assessment and implications of generalized outcome expectancies. Health Psychology, 4, 247. http://dx.doi.org/10.1037/0278-6133.4.3.219

Seligman, M. (2003). Learned Optimism: How to change your mind and your life. New York. Pocker books.

Seligman, M. E., Nolen, N. P., Hochsem, A. N., Thomson, N. S., \& Thomson, G. K. (1990). Heamed Optimism. New York: Norton.

Seligman, M. E. P. (1990). Learned optimism. New York: Pocket Books.

Seligman, M. E. P. (1991). Learned optimism. New York: Knopf.

Shukri, M. (1999). Optimism and Pessimism and their relationship to the Methods for Addressing Hardship in Psychological Studies. Psychologists Association, 9(34), 387-416.

Walker, V., \& Brokaw, L. (1992). Becoming aware: A look at human relations and personal adjustment.

Yates, S. M. (2000). Student optimism, pessimism, motivation and achievement in mathematics: A longitudinal study. In T. Nakahara, \& M. Koyama (Eds.), Proceedings of the 24th Conference of the International Group for the Psychology of Mathematics Education (Vol. 4, pp. 297-304).

\section{Copyrights}

Copyright for this article is retained by the author(s), with first publication rights granted to the journal.

This is an open-access article distributed under the terms and conditions of the Creative Commons Attribution license (http://creativecommons.org/licenses/by/3.0/). 